\title{
Overview of DVB-RCS+M and its Development
}

\author{
Harald Skinnemoen ${ }^{1}$ \\ P T Thompson ${ }^{2}$ \\ ${ }^{1}$ AnsuR Technologies AS, Norway \\ ${ }^{2}$ CCSR, University of Surrey, Guildford, UK
}

\begin{abstract}
SUMMARY
The use of DVB-S and DVB-RCS for conducting two-way communications from small satellite terminals has become well established in Europe and elsewhere. During the development of DVB-RCS the possibility of limited use for satellite terminals that were moving was considered in January 2004 and incorporated into the Guideline document associated with the Standard in April 2005. It was noted, however, that this matter be addressed further as a future development. This paper addresses the steps that have been taken since then to realise this objective.

During the last few years, it has been shown that the DVB-S2/DVB-RCS specifications are good candidate baselines for the efficient implementation of broadband services to mobile users. Results of these studies were gathered in a study mission report from the TM-RCS adhoc group. It was demonstrated that both forward and return channels waveforms are impacted by the mobile usage, and should be addressed in the scope of a update of the DVBRCS standard.
\end{abstract}

Technical analysis identified that DVB-RCS, as it had been originally designed for fixed satellite services, provided most of the features required by mobile applications above $5 \mathrm{GHz}$, and could be turned into a competitive solution with a few carefully crafted modifications. Subsequent activities within the TM-RCS Group have led to an efficient and robust standard that incorporates mobility more definitely into version 1.5.1 of the DVB-RCS specifications, along with appropriate detailed 'Guidelines' documentation giving expanded description of the standard and its use and application.

Key Words: DVB-S2, DVB-RCS, RCS+M, Mobile satellites systems, standards.

\section{Introduction}

The use of DVB-S and DVB-RCS for conducting two-way communications from small satellite terminals has become well established. During the development of DVB-RCS [1], the possibility of limited use for satellite terminals that were moving was considered in January 2004 and, after some discussion, incorporated into the Annex of the Guideline document associated with the Standard in April 2005 [2]. When this limited capability to handle mobile user terminals was incorporated into Annex L of the DVB-RCS Guideline document it was noted that, with regard to the $\left(\mathrm{ETRI}^{3}\right)$ contributions on the matter covering mobility for

\footnotetext{
${ }^{1}$ E-Mail: harald@ansur.no

2 Correspondence to: P. Thompson@ surrey.ac.uk

${ }^{3}$ ETRI, Electronics and Telecommunications Research Institute, Korea
} 
DVB-RCS much more extensively, that "This may be the topic of a future development if decided by the DVB CM and DVB-TM (DVB-RCS Chairman)".

Subsequently in 2005 the ASMS-TF4 requested that the DVB TM-RCS Ad Hoc Group be reestablished to work on this subject further, by submitting a request under the ASMS-TF members agreement. This was presented at the 63rd meeting of DVB Technical Module (DVB-TM) in November 2005. At this meeting the Chairman proposed that the DVB-TMRCS (under Prof. G Stette) undertakes studies into the feasibility and requirements to extend DVB-RCS to a level that incorporates mobility more definitely and therefore supplements the guidelines. The DVB TM-RCS should also recommend how to do this, by modifying the current specification or the development of a variant or a new standard. A report back was programmed for the March 2006 meeting of the DVB-TM.

The study mission report was prepared from many contributions from TM-RCS members, reusing materials from studies and activities targeting broadband mobile services based on DVB-RCS standards. These studies and activities include but are not limited to the following:

- EU FP6 project: "MOWGLY”, led by Alcatel Alenia Space (France) [5],

- ESA Artes-3 study: "DVB-RCS adaptation to mobile", led by EADS Astrium (France),

- ESA Artes-1 study: "Study of DVB-S2/DVB-RCS Broadband Mobile System", led by Space Engineering (Italy),

- EU FP6 network of excellence "SatNEx", led by DLR (Germany),

- “MoBISAT”, by ETRI (Korea) [6-8].

While DVB-RCS is a full two-way specification, at the physical and link level, DVB-RCS [1] addresses the return link segment of the two-way system. DVB-S or DVB-S2 [3, 4] is utilised on the forward link, and there was also need to address several issues specific to mobility of the remote terminal for these standards. Initially it was not clear if medications of the forward links also were needed, but there was a strong wish to try to avoid that in TM-S2 if changes were only for DVB-RCS mobility aspects.

\section{Targeted services and products}

The typical targets are broadband interactive services to mobile, consisting in IP connectivity, high speed internet and intranet accesses and others IP Multimedia services such as VoIP, streaming, IPTV, contents distribution, video and radio on demand. These applications are also supported by current fixed DVB-RCS systems.

Market analysis performed in previous studies highlighted that the most promising markets for DVB-RCS mobile applications are those related to public transportation (cruise ships and ferries for the maritime domain, buses and trains for the land based domain and planes for the aeronautical domain) and to a lesser extent for private transportation. This is illustrated in the following figures. These markets are such that a DVB-RCS solution could benefit from a captive audience during several hours in duration and under conditions where broadband access aggregation of several users would result in higher data rates. This is an important distinction from mobile systems as for handhelds. Furthermore, the sensitivity to terminal

\footnotetext{
${ }^{4}$ Advanced Satellite Mobile Systems - Task Force
} 
antenna size could be generally lower for this market than for the individual user terminal market (e.g. the car based market).

A potential market that is gaining increasing interest is the governmental/military satellite communication market. This system spans all mobile domains, initially using commercial FSS satellites.

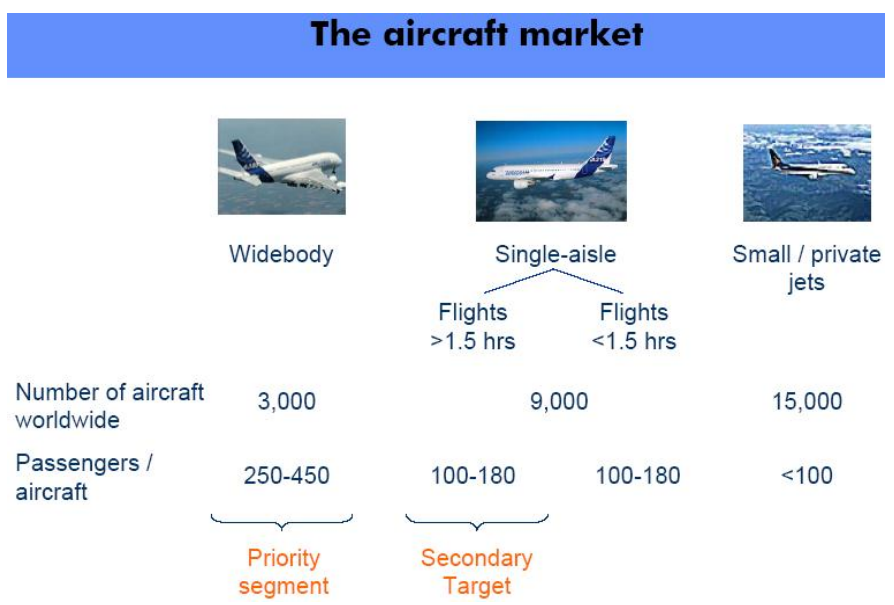

Figure 1 Estimated aircraft broadband market

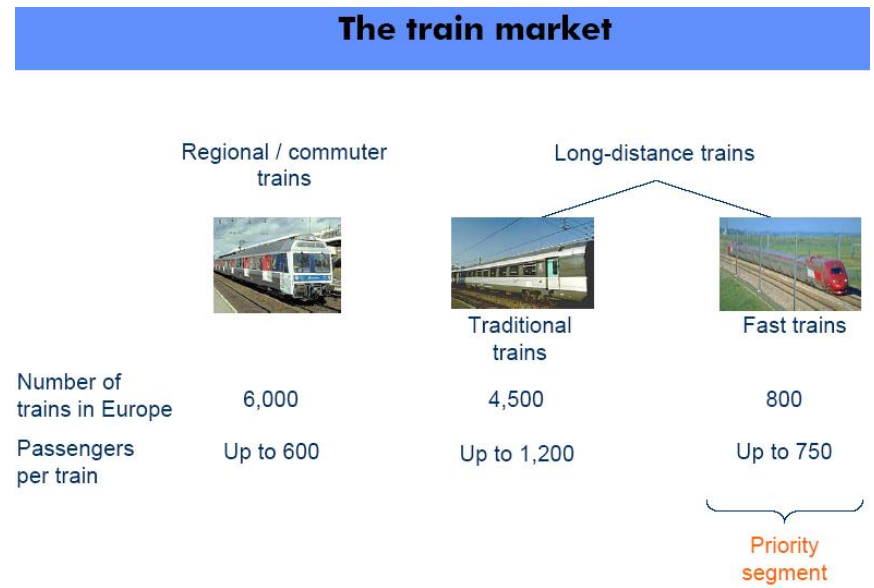

Figure 2 Estimated train broadband market

Note: the train market figures do not consider the North American and Asian market.

\section{The maritime market}

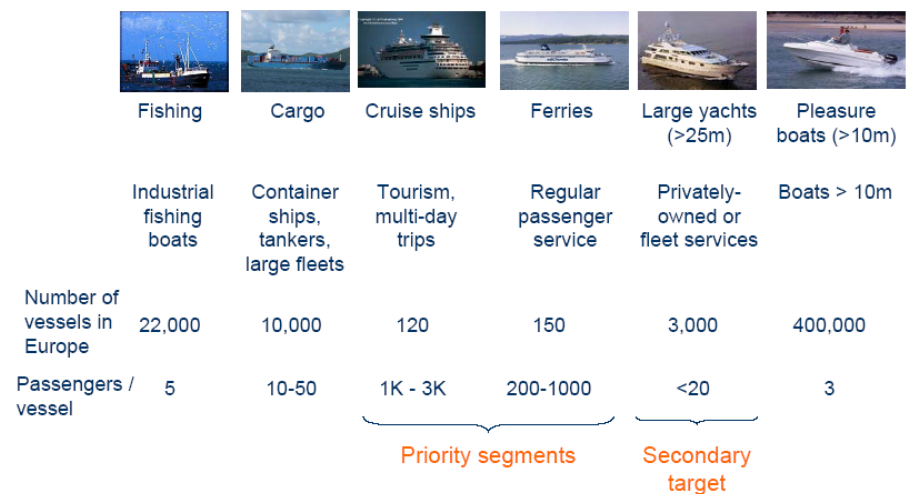

Figure 3 Estimated maritime broadband market 


\section{Consideration of Commercial Requirements}

In considering further the mobility interest in DVB RCS the DVB Commercial Module (DVB-CM) addressed some key specific points. First the technical specifications need to be defined for the following commercial requirements which cover the interests of end users, service providers and network operators. In addition the technical recommendations shall not prevent service providers and network operators from taking into account all issues covered by local and national laws. The main issues for the DVB-RCS+M specification, or just $\mathrm{RCS}+\mathrm{M}$, are summarized below:

1. RCS+M focuses on the identified market segments and targeted services listed above.

2. It specifies Quality of Service classes supporting services with real-time requirements, and services with non real-time requirements.

3. RCS+M is neutral with respect to applications

4. It ensures interoperability between multiple vendor satellite user equipment.

5. It ensures provision of secure transactions between end users and service providers, authentication, integrity, and confidentiality, and non-repudiation of the services, and prevention of unauthorised access.

6. RCS+M may not pose additional requirements on standards or equipment not intended for mobile use.

7. It aims at minimising changes to existing standards, focussing only potential essential changes required e.g. to meet regulatory requirements. It also aimed at adopting, where relevant, mechanisms and mobility-relevant aspects from other existing international standards..

8. Adaptations/changes to existing standards addresses the following technical issues, already identified in the mobile RCS study mission report:

- Mobile satellite channel impairments, Doppler effect, Mobility management, and regulatory environment.

9. Interoperability between DVB-RCS+M systems for different segments is secured as required.

10. Has well defined internal interfaces

11. Allows for terminal upgrades through reliable downloads of new terminal operational software and application software.

12. Adresses remote monitoring and configuration of the satellite user equipment.

13. It meets all appropriate regulatory requirements set forth by international regulatory bodies (ITU, CEPT, FCC, etc).

14. Has a limited number of profiles to reduce possible variants of equipment

15. Maximises the elements of commonality between the different profiles.

16. Was be completed as soon as possible, ideally by mid 2007. (Work was started later than anticipated but it completed in 2007) 
17. RCS+M allows the usage of several end-user equipments connected to the terminal through standard WLAN or wired LAN technologies.

It was also agreed to consider an SCPC (continuous carrier) configuration of DVB-RCS employed on a fixed traffic allocation basis to provide a more efficient system when high levels of aggregated traffic is experienced (for example on cruise liners).

Figure 4 below depicts the conceptual configuration of DVB-S2/DVB-RCS services to mobile users.

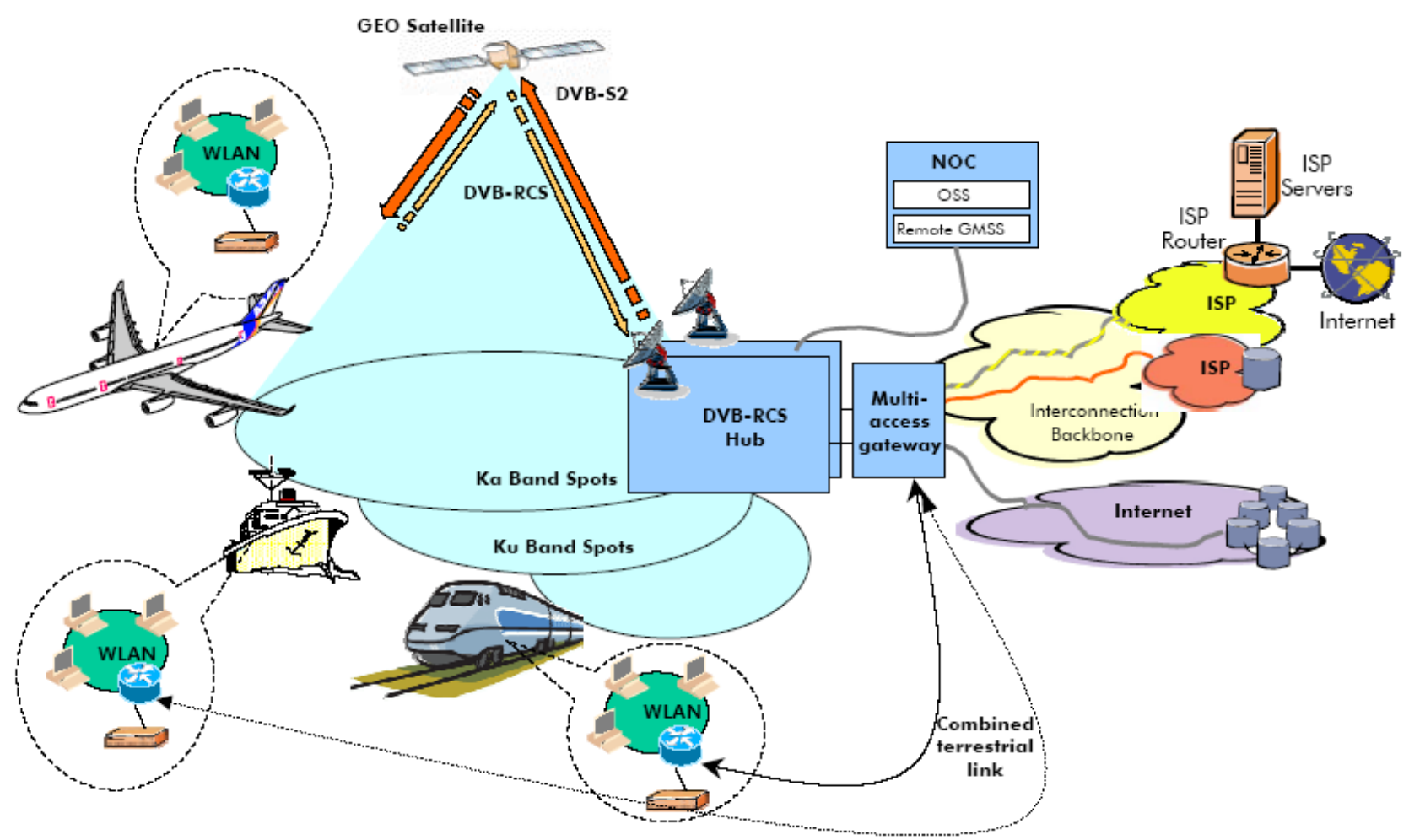

Figure 4 Configuration of DVB-S2/DVB-RCS services to mobile users

\section{Consideration of Annex L of the current DVB-RCS Guidelines document}

The previous DVB-RCS Guidelines Document [2] advises on how mobile users may adopt DVB-RCS but such use is restricted due to a number of assumptions and approaches contained in the Guidelines, namely:

1. Focus on the Indoor Unit (modem) part of the terminal

2. Air interface for AWGN channel, i.e. only favourable propagation conditions;

3. No multipath and shadowing constraints assumed;

4. LOS, fade degradation compatible with system link budgets assumed;

5. No specified enhancement to mobile terminal for mobility;

6. No specified enhancement to gateway for mobility;

7. Limited Mobility covered by selection/optimization of parameters in a non-standardised manner. 
Thus the use of Annex $\mathrm{L}$ of that Guidelines Document still results in a non-optimum arrangement for mobile users and fails to deliver a clear and unambiguous standard to meet various mobile operational environments.

\section{Updating of the DVB-2 and DVB-RCS for mobile users}

A review of the appropriate documentation was done and results in the following key points that need addressing:

1. Network wide issues needed to be addressed, as there is a need to accommodate both fixed and mobile terminals within the network and the Hub may need to be modified to handle this feature.

2. Need to handle hand-off between beams which was currently not supported or described in any specific detail to ensure interoperable implementation. Thus elements of handover management, detection and preparation of beam handover and handover execution with its associated signalling needed addressing.

3. Consider modulation/demodulation robust to frequency offset, especially at low data rates where the Doppler shift is significant and timing uncertainties are higher.

4. Introduce elements that address the terminal location and velocity as well as the use of Doppler pre-compensation to adequately handle Network Clock Reference (NCR) clock recovery and other timing issues.

5. An issue arises with synchronisation, both acquisition and maintenance of it. Introduction of an additional guard time to cater for this could result in a large overhead to the throughput.

6. A robust protocol was required to maintain the connection during the short but frequent non-LOS induced log-on/off cycling.

7. Address the control of signal and traffic flows, as unacceptable transmission stops will otherwise occur during fast fading.

8. Consider not only AWGN or slow fading but some mobile applications require transmission over fast-fading channels with the potential of shadowing. Need to consider both LOS and non-LOS propagation conditions, consequently countermeasure such as interleaving may need to be developed and included in the standard.

9. For operation with very small aperture antennas it was seens as likely that some form of additional spectrum spreading to meet off-axis EIRP spectral density limits may be required on the Forward Link (DVB-S2) and to a higher degree on the Return Link (DVB-RCS). As this can result in significant bandwidth expansion its use should be kept to essential cases. 


\section{Detailed Technical Considerations}

\section{Doppler}

The table below gives some typical values in $\mathrm{Ku}$ band for Doppler shift, Doppler drift and time drift, for different type of mobile terminals (speed and accelerations). The tables provide worst case Doppler shifts, assuming terminal motion towards the satellite and minimum elevation angle (leading to a minimum relative angle $\theta$ between the vehicle and the satellite $\theta=0$ ), for all considered system scenarios.

\begin{tabular}{|c|c|c|c|c|c|c|c|c|}
\hline Type of Mobile & Speed & $\begin{array}{l}\text { Acceleration } \\
\qquad(\mathbf{m} / \mathbf{s} 2)\end{array}$ & $\begin{array}{c}\text { Doppler } \\
\text { frequency } \\
\text { variation }\end{array}$ & $\begin{array}{c}\text { Doppler } \\
\text { frequency shift } \\
\text { (Uplink) }\end{array}$ & $\begin{array}{c}\text { Doppler } \\
\text { frequency shift } \\
\text { (Downlink) }\end{array}$ & Time drift & $\begin{array}{c}\text { Frequency } \\
\text { drift } \\
\text { (UL) }\end{array}$ & $\begin{array}{c}\text { Frequency } \\
\text { drift } \\
\text { (DL) }\end{array}$ \\
\hline Maritime & $25 \mathrm{~km} / \mathrm{h}$ & $5 \mathrm{~m} / \mathrm{s} 2$ & $2,31 \mathrm{E}-08$ & $336 \mathrm{~Hz}$ & $295 \mathrm{~Hz}$ & $23,1 \mathrm{~ns} / \mathrm{s}$ & $242 \mathrm{~Hz} / \mathrm{s}$ & $213 \mathrm{~Hz} / \mathrm{s}$ \\
\hline Vehicular (bus, car, truck) & $120 \mathrm{~km} / \mathrm{h}$ & $10 \mathrm{~m} / \mathrm{s} 2$ & $1,11 \mathrm{E}-07$ & $1611 \mathrm{~Hz}$ & $1417 \mathrm{~Hz}$ & $111 \mathrm{~ns} / \mathrm{s}$ & $483 \mathrm{~Hz} / \mathrm{s}$ & $425 \mathrm{~Hz} / \mathrm{s}$ \\
\hline Train & $350 \mathrm{~km} / \mathrm{h}$ & $5 \mathrm{~m} / \mathrm{s} 2$ & 3,24E-07 & $4699 \mathrm{~Hz}$ & $4132 \mathrm{~Hz}$ & $324 \mathrm{~ns} / \mathrm{s}$ & $242 \mathrm{~Hz} / \mathrm{s}$ & $213 \mathrm{~Hz} / \mathrm{s}$ \\
\hline Aeronautical (< sound speed) & $330 \mathrm{~m} / \mathrm{s}$ & $17 \mathrm{~m} / \mathrm{s} 2$ & $1,10 \mathrm{E}-06$ & $15950 \mathrm{~Hz}$ & $14025 \mathrm{~Hz}$ & $1100 \mathrm{~ns} / \mathrm{s}$ & $822 \mathrm{~Hz} / \mathrm{s}$ & $723 \mathrm{~Hz} / \mathrm{s}$ \\
\hline Satellite movement (GSO) & $3 \mathrm{~m} / \mathrm{s}$ & $0 \mathrm{~m} / \mathrm{s} 2$ & $1,00 \mathrm{E}-08$ & $145 \mathrm{~Hz}$ & $128 \mathrm{~Hz}$ & $10 \mathrm{~ns} / \mathrm{s}$ & $4,8 \mathrm{~Hz} / \mathrm{s}$ & $4,3 \mathrm{~Hz} / \mathrm{s}$ \\
\hline
\end{tabular}

Table 1 Doppler aspects of mobile user terminals

\section{Propagation channel models}

Two propagation situations are envisaged. One called LOS represents the case where the propagation path is predominantly Line of Sight (LOS) with little or no additional signal paths. This may be the case for aeronautical and maritime services. The second relates to conditions where the direct line of sight signal may be blocked resulting in only reflected signals being present and is classifies as the non-LOS situation.

\begin{tabular}{|c|c|c|c|}
\hline State & & Description & Characteristic \\
\hline \multicolumn{2}{|c|}{ LOS } & $\begin{array}{c}\text { Line of Sight } \\
\text { (Directive antenna) }\end{array}$ & $\begin{array}{c}\text { Rice distribution } \\
\mathrm{K}=17 \mathrm{~dB} \text { (typical) }\end{array}$ \\
\hline \multirow{3}{*}{ Non-LOS } & Shadowing & $\begin{array}{c}\text { Shadowing (example, due to } \\
\text { single trees) }\end{array}$ & $\begin{array}{c}\text { Small scale fading: Rice } \\
\text { Large scale fading: Log-normal }\end{array}$ \\
\cline { 2 - 4 } & Blockage & $\begin{array}{c}\text { Blockages (example, due to } \\
\text { buildings, bridges and tunnels) }\end{array}$ & $\begin{array}{c}\text { No signal received or signal below } \\
\text { noise floor }\end{array}$ \\
\hline
\end{tabular}

\section{Table 2 Propagation States}

Common mobile satellite channel characteristics for each state could be described as in Table 2. The channel model for moving vehicles such as bus, ship, or train, can be successfully modelled with a three state Markov-Chain model, covering both LOS and Non-LOS cases. Channel state transition and occupancy probabilities depend on the considered propagation environment by channel correlation and Doppler spectrum. 


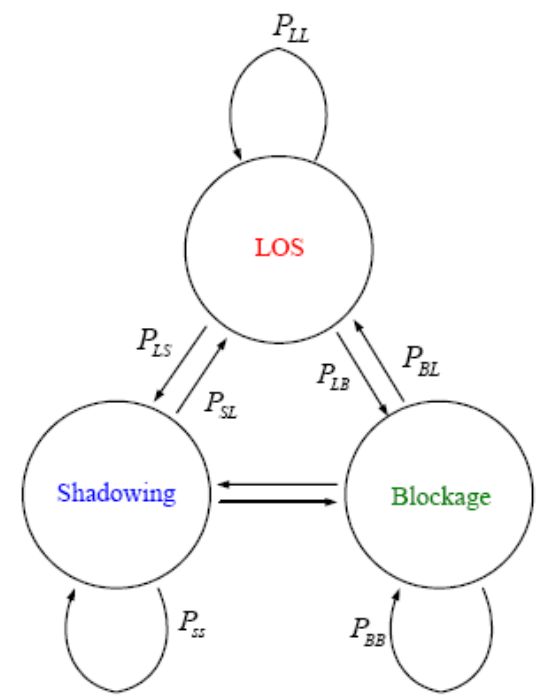

Figure 5 Three state Markov Channel Model

Generally, high speed trains cause a smaller fading time correlation and results in lower fade durations. As the train moves along the railroad, nearly space-periodic fading events are experienced whenever the line-of-sight between the train antenna and the satellite is shadowed by various obstacles like electric trellis bridges or overhead cable posts with bracket. This can induce peculiar fading occurrence that affects the system performance remarkably as the deep fading due to periodic fade occurrences with the rate proportional to the train speed and the power arch spacing is superimposed on the statistical mobile satellite channel factor. In fact, when the train approaches the power arches, knife-edge diffraction affects the transmitted signal producing a space-varying attenuation that depends on the structure.

\begin{tabular}{|c|c|c|c|}
\hline \multirow{2}{*}{$\begin{array}{c}\text { Train Speed } \\
(\mathrm{km} / \mathrm{hr})\end{array}$} & FW $=0.5 \mathrm{~m}$ & $\mathrm{FW}=1.0 \mathrm{~m}$ & \multirow{2}{*}{ Fade Occurrence Time (s) } \\
\cline { 2 - 4 } & 6 & 12 & 0.6 \\
\hline 300 & 9 & 18 & 0.9 \\
\hline 200 & 18 & 36 & 1.8 \\
\hline 100 & 90 & 180 & 9.0 \\
\hline 20 & 90 & & \\
\hline
\end{tabular}

Table 3 The impact of power arches

In Table 3, the occurrence of fading events and the time required to cross the Fresnel zone due to two different power arch topology are presented as a function of the train speed (considering the distance between two consecutive power arches equal to $50 \mathrm{~m}$ ).

In particular, two fade widths of 0.5 and $1.0 \mathrm{~m}$ have been chosen to take into account the most typical railroad layouts, which produces typical attenuations of $3 \mathrm{~dB}$ (post with bracket), $8 \mathrm{~dB}$ (Electric Trellis Bridge) respectively.

Considering these parameters, it can be seen that in the worst case scenario, which refers to a train speed of $300 \mathrm{~km} / \mathrm{h}$ and to a fade width of $0.5 \mathrm{~m}$ the fading events occur every $600 \mathrm{~ms}$ and last for $6 \mathrm{~ms}$. 
In a burst transmission like DVB-RCS system, fade occurrences cause packet loss more frequently than normal, since in most cases of this kind of transmission, the length of an ATM/MPEG packet is usually within the fade duration, one or more packets can suffer from deep fading over the fade duration. Therefore, the worst case occurs when the train speed is high and the fade is deep in the burst transmission.

For more detail on the specifics of propagation effects see references [9-13], see also [18] for some simulation results.

\section{Modem performance}

Figure 6 illustrates the effects of receiver speed on PER with a $250 \mathrm{kbaud}$ signal under LOS propagation. We see that with Doppler spread a performance degradation occurs compared to the fixed terminal service case. Therefore, the Eb/No value has to be increased provide a good QoS. As can be noted from the figure there are losses of around $1.8 \mathrm{~dB}$ and $2.3 \mathrm{~dB}$ respectively when considering speeds of $300 \mathrm{~km} / \mathrm{h}$ and $160 \mathrm{~km} / \mathrm{h}$ due to the lower fade correlation.

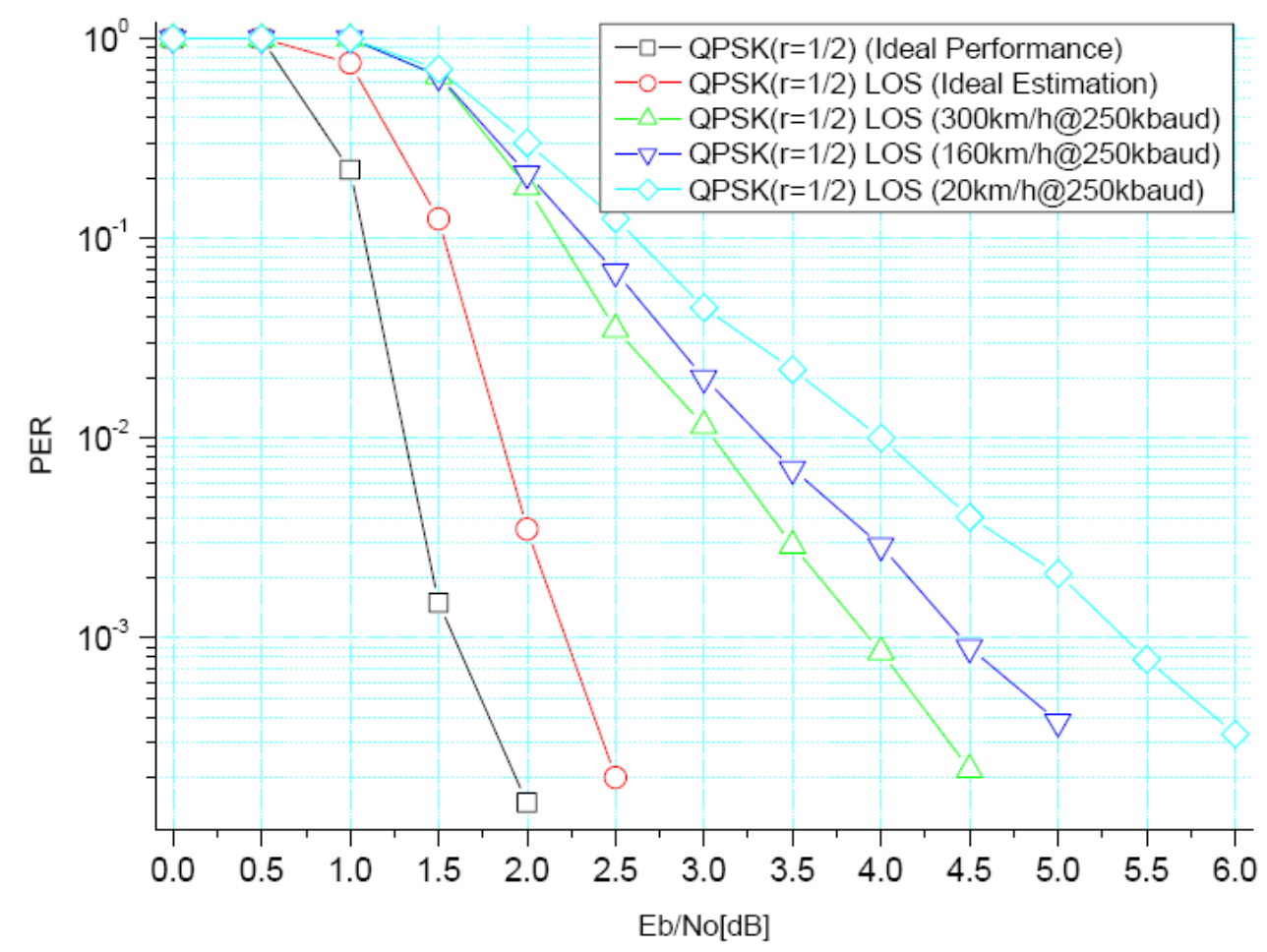

Figure 6 Effects of receiver speed on PER - LOS 


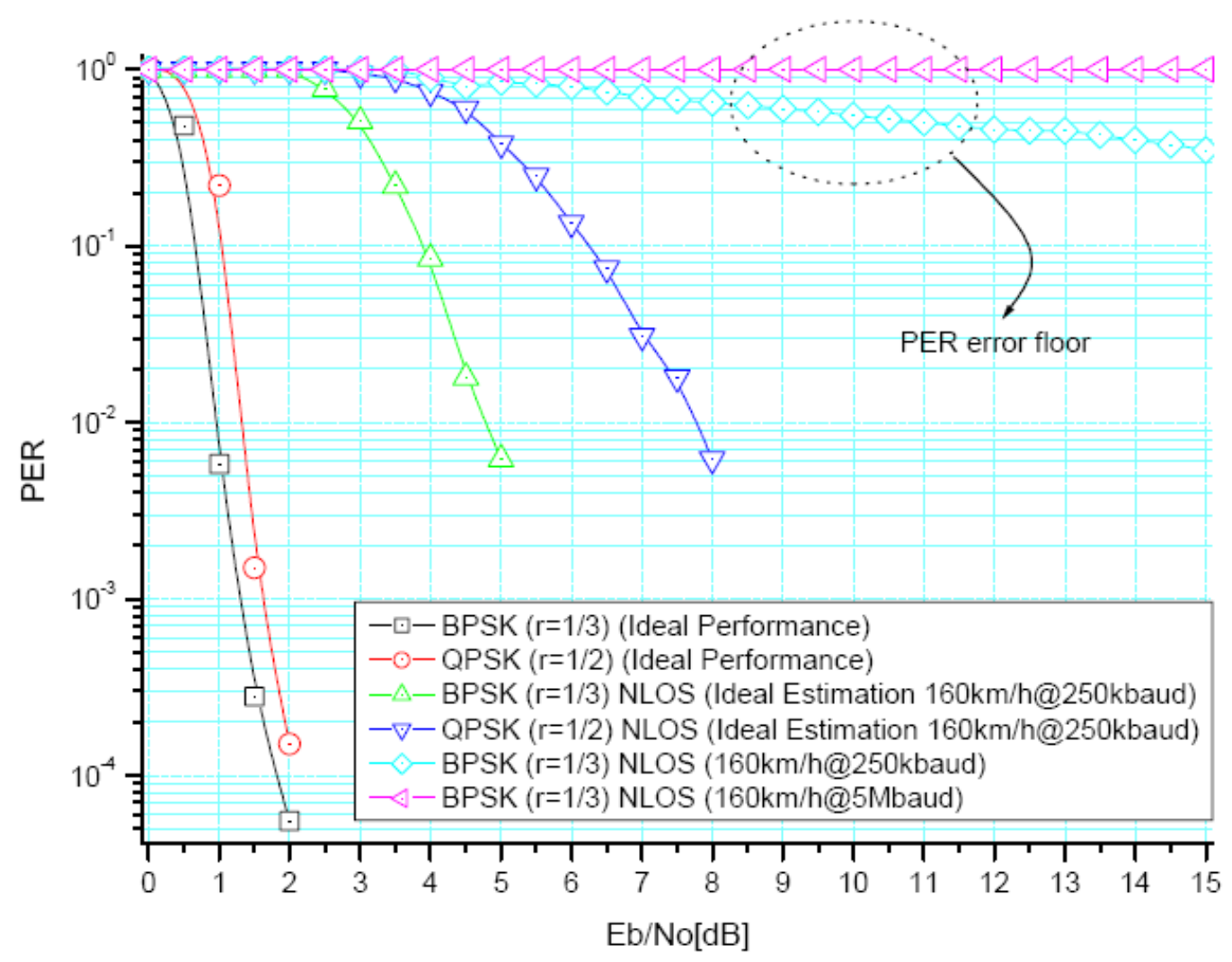

Figure 7 Effects of receiver speed on PER - non-LOS

Non-LOS propagation PER error results are shown in figure 7. The error floor is due to Doppler frequency offset/phase estimation errors in the non-LOS mobile environment. A coherent QPSK receiver is very likely unable to properly track the large phase variation throughout the packet, thus causing phase tracking slips. This poor estimation performance cannot be improved simply by increasing the Eb/No value. This implies that there is only a limited possibility to recover the received data signal under deep fading duration at physical layer by increasing only Eb/No value. The adoption of appropriate Application Layer FEC and interleaving have been demonstrated as being effective in combating such fading.

\section{Synchronisation}

Another point has to be considered to support the mobile environment is time accuracy. An initial log-on position may be different from time to time in mobility condition. And a satellite beam coverage usually ranges from hundreds kilometres to thousands kilometres in diameter. So even in the same satellite beam coverage, in contrast to the fixed service, there is a significant time difference in travelling between Hub and terminal and it varies according to the terminal's initial log-on position. It turns out the initial acquisition of synchronization needs to be automatically accommodated upon the knowledge of initial position and velocity. Positioning system (such as GPS, Galileo) may be employed in the terminal to predict and pre-compensate the time difference for initial synchronization, but the reasonable positioning knowledge is not always available by GPS receiver. The velocity and acceleration information should be available to the terminal and possibly to Hub for current initial synchronization. 


\section{Handover}

The mobile terminal should be handed over from one beam to another (i.e. from one transponder to another) as the mobile terminal moves between the satellite coverage areas. Therefore DVB-RCS+M had to take into consideration the handover between beams that is required in the multi-beam systems that are expected to be active in the next few years.

\section{Power control}

A closed loop power control method is employed in DVB-RCS, but this method is not very suited to the mobile terminal. Since the mobile terminal should be able to access the hub system in any satellite coverage or any channel condition (cloud, rain fading etc.), the power level of the terminal should be always kept to the level of access allowance regardless of mobility. The probability of initial access failure may be increased if the power level is not properly controlled. For this reason, the continuous performance of mobile terminal needed to be improved by using, for example, an open-loop power control method.

\section{Impact on the Gateway/NCC}

Mobility has a small impact on the Gateway/NCC design/operation. The additional functions include:

- Physical layer adaptations, e.g. spectrum spreading

- Forward link and return link handover

- Modified traffic routing/buffering within the Gateway (associated with the forward link handover)

- Additional signalling generation and distribution (associated with the forward link handover)

- New resource control functions (logical resources associated with both forward link and return link handover, physical resources associated with the return link handover)

- Event synchronisation (to support both forward and return link handover).

\section{Resource Allocation}

A special resource allocation protocol will be required in order for the NCC to decide whether it should allocate capacity to terminals which operate in bad propagation environments. This will require a decision to be made on whether the blocking of the signal is temporary with small duration or has longer duration. Thus, an enhancement of the present standard is required to overcome the forward and return link signal blocking and the critical subsequent problems on traffic performance. The main focus required here was to devise a unified protocol-level approach for resolving the emerging problems. Reference [15] gives some further background on this subject.

\section{Diversity Considerations}

Various type of diversity are in principle possible [14]. Realistically however, the space diversity option is not very applicable to most mobile systems because of the high cost of the terminal antenna arrangement. Delay diversity for DVB-RCS is a viable option but needs to be done in an intelligent manner in order to save bandwidth. If it is implemented in an efficient manner it can safeguard against the periodic fading events along the rail track as well as against signal blockage in tunnels. 


\section{Application Layer FEC}

It is possible that Application Layer FEC may be advantageous at upper layer level to recover packet losses, especially in a mobile application. Use in the Forward Link may be attractive in order to cope with packet loss due to fading.

Raptor codes have been recently adopted as application layer FEC in the frame of the 3GPP MBMS (Multimedia Broadcast/Multicast Services) [16]. The associated overhead is low and in addition it has low hardware and software complexity required for the encoding /decoding operation with respect to other coding alternative. An additional important characteristic of Raptor codes is the fact that the code is systematic thus allowing information packets to be recovered even by receivers not equipped with Raptor Decoders provided that no packet loss is experienced for that receiver.

A long block coding approach operating at the MAC layer has also been standardised in DVB-H, i.e. the MPE-FEC. This code operates on MPE sections. An MPE-FEC frame is arranged as a matrix with 255 columns and a flexible number of rows with each matrix position corresponding to a byte.

Thus, it appears that long block coding like Raptor codes represent a valid countermeasure against the periodic fading encountered in a railway environment which is suitable for several applications in addition to the reliable multicasting [17] applications for which it was originally devised. Consequently Application Layer FEC has been incorporated in the specification.

\section{Spreading}

To accommodate the use of small terminals, a DVB-S2 forward link transmission can for RCS+M be spread in bandwidth. This allows not increasing the power density but the penalty is, of course, increased bandwidth. The following diagram is representative of a possible implementation of the spreading functionality that can be added to a DVB-S2 compliant modulator and demodulator. This is considered representative of practical implementations (alternative schemes are possible provided the signal transmitted is equivalent). The speading part was one of the issues one considered might need the DVB TM-S2 group to reopen the DVB-S2 specification, but the in the way finally done, the signal coming out from the receiver spreading chain can be processed by a classical DVB-S2 receiver. 


\section{Modulator part for spreading}
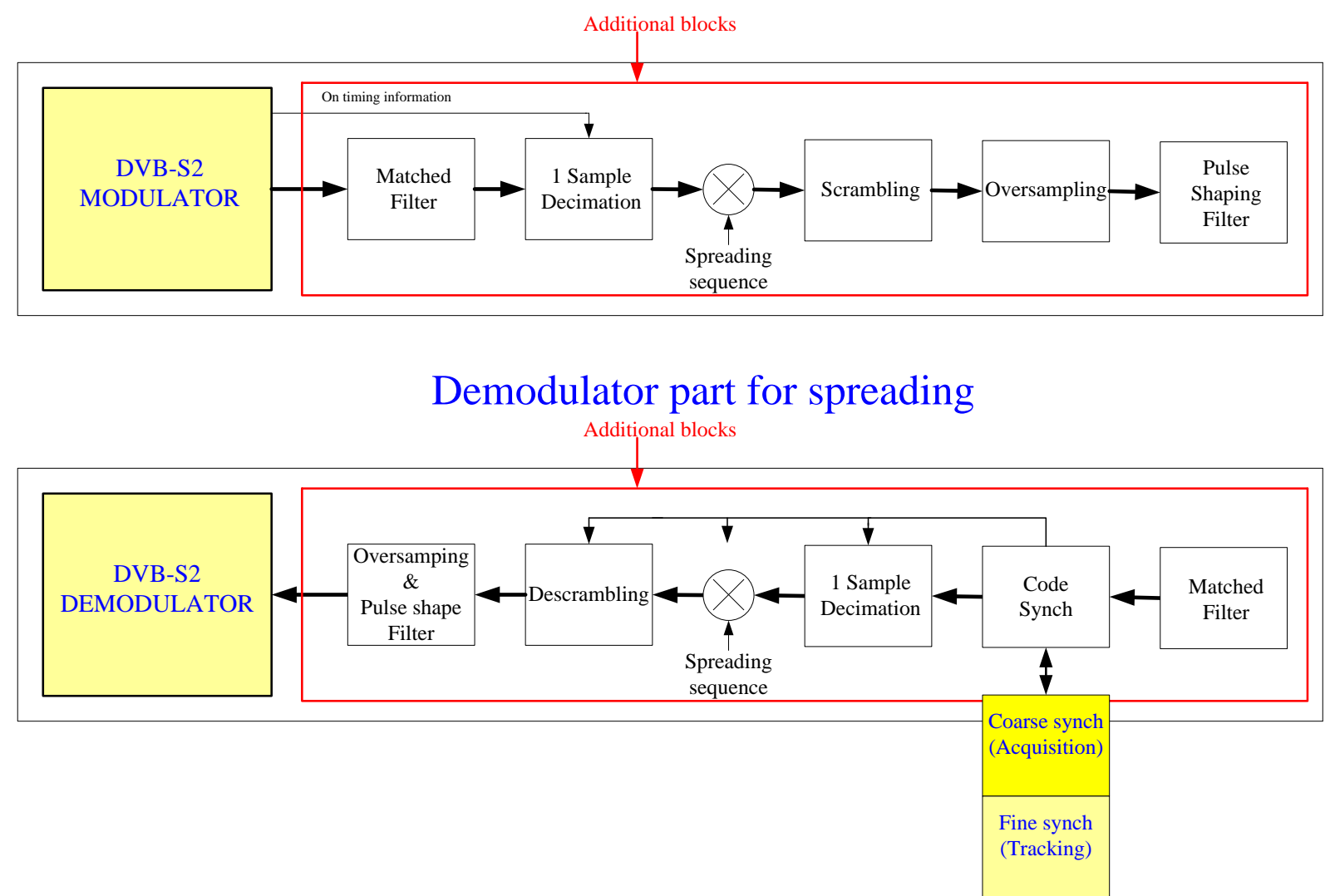

Figure 1: Block diagram of the demodulator with the spreading functionality

\section{$\mathrm{SCPC}$}

\subsection{Fast re-synchronization in mobile scenarios}

\section{Schedule and approach}

A two step approach was adopted for the standards work. The first step covered modification for maritime and aeronautical use (i.e. predominantly LOS services) with train based standards (predominantly non-LOS) services being handled in the second stage.

Furthermore, a work programme was developed along the following lines:

1. Development of a Standard document proper, in a form that includes the "base" standards by reference and defining special functionality directly. This document would be delivered to the TM in two versions; the first would only address line-of-sight environments in full detail. The second version would address non-line-of-sight environments as well, and will be built from the first version while observing backwards compatibility. This done in a manner similar to that adopted for DVB-H and DVB-T, except the published ETSI document would cover both aspects.

2. A guidelines document, containing explanatory material, implementation suggestions and preferred ways of operating systems; in the same manner as the existing DVB-RCS and DVB-S2 guidelines. 
Thus a revised version of EN 301790 has been produced which is version V1.5.1 and it has been published in the DVB Blue Book as document A054r4.1 [19] and at the time of writing this article was completing the ETSI One-step Approval Procedure.

The revisions contain some general changes as well as some specific to mobility and these are depicted in figures 8 and 9.

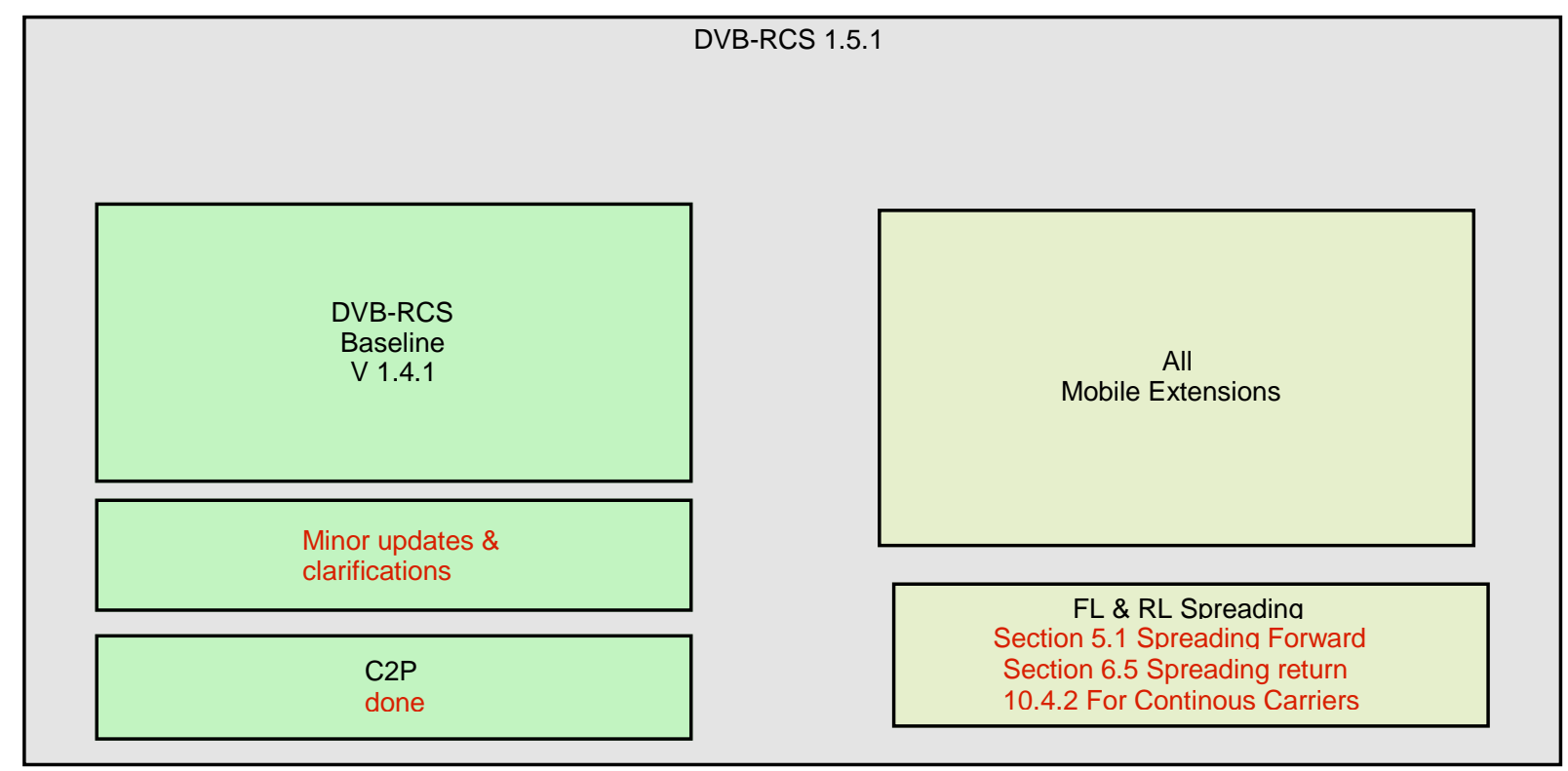

Figure 8 General updates to EN 301790

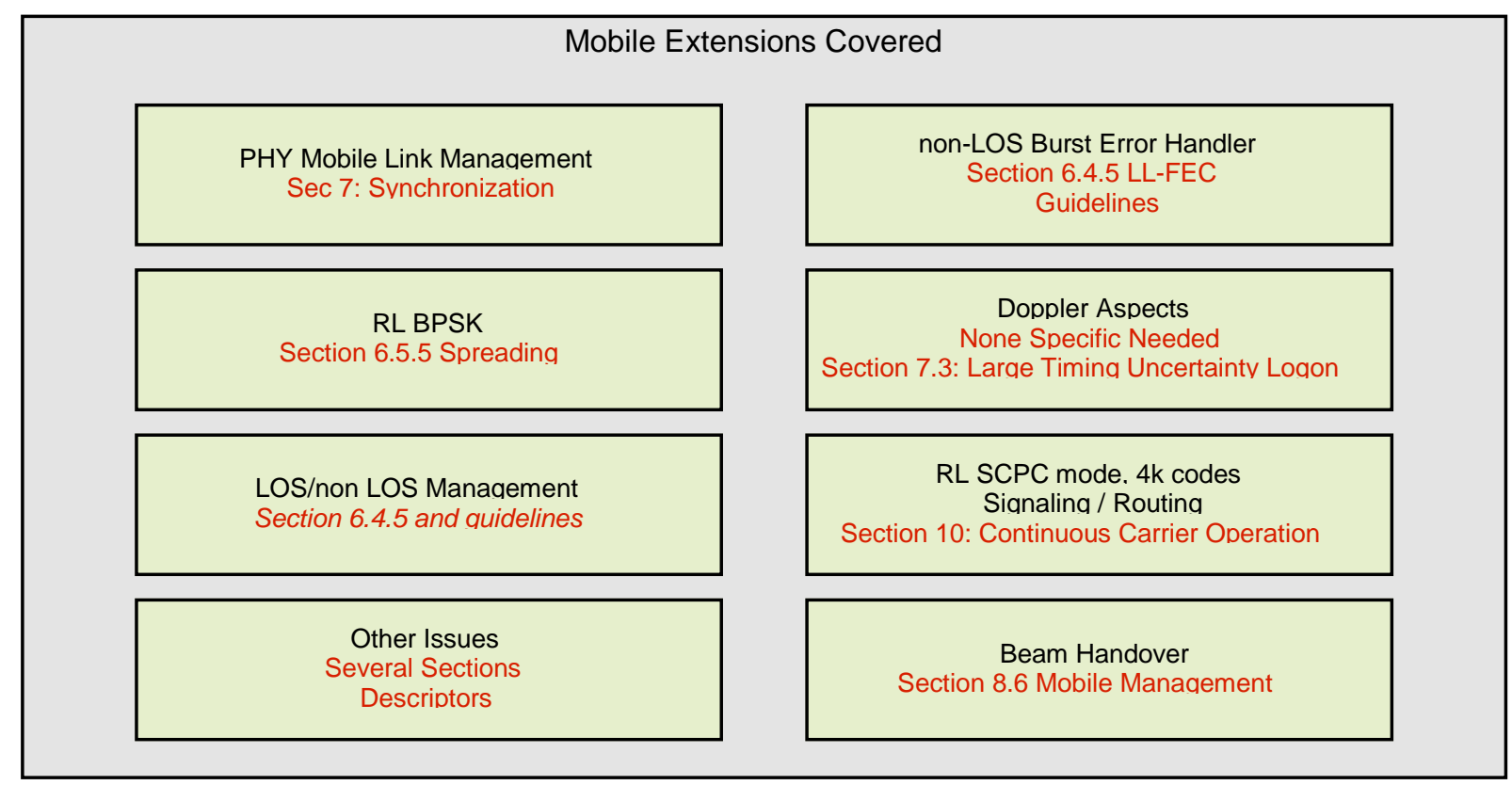

Figure 9 Specific updates to EN 301790

The scope of this revised document can be readily appreciated by consideration of the RCST compliance table given in Table 4. 


\begin{tabular}{|c|c|c|c|c|c|c|c|}
\hline PROFILE NAME & Baseline & \begin{tabular}{|c|} 
ATM \\
(option)
\end{tabular} & $\begin{array}{l}\text { MPEG2 } \\
\text { (option) }\end{array}$ & $\begin{array}{c}\text { Baseline } \\
\text { DVB-S2 } \\
\end{array}$ & \begin{tabular}{|c|} 
ATM \\
DVB-S2
\end{tabular} & $\begin{array}{l}\text { MPEG2 } \\
\text { DVB-S2 }\end{array}$ & Mobile \\
\hline $\begin{array}{r}\text { Access scheme } \\
\text { Fixed MF-TDMA } \\
\text { Dynamic MF-TDMA }\end{array}$ & • & • & $\bullet$ & $\bullet$ & • & • & $\dot{\circ}$ \\
\hline $\begin{array}{lr}\text { Traffic Burst Format } & \text { ATM } \\
\text { MPEG2 }\end{array}$ & - & - & $\bullet$ & - & - & $\bullet$ & $\bullet$ \\
\hline $\begin{array}{rr}\text { Connectivity } & \text { IP } \\
& \text { Native ATM } \\
\text { Dynamic (C2P) }\end{array}$ & • & $\begin{array}{l}\bullet \\
\bullet \\
\end{array}$ & $\begin{array}{l}\bullet \\
\\
0\end{array}$ & ० & $\begin{array}{l}\bullet \\
\bullet \\
\end{array}$ & $\begin{array}{l}\bullet \\
\\
0\end{array}$ & - \\
\hline $\begin{array}{rr}\text { Channel Coding } & \text { RS } \\
& \text { Convolutional } \\
\text { Turbo } \\
\text { CRC }\end{array}$ & - & : & $\begin{array}{l}\bullet \\
\bullet \\
\bullet \\
\bullet\end{array}$ & $\begin{array}{l}\bullet \\
\bullet \\
\bullet \\
\bullet\end{array}$ & : & - & $\bullet$ \\
\hline $\begin{array}{r}\text { Capacity Requests and } \\
\text { management information } \\
\text { Prefix } \\
\text { Data Unit Labelling } \\
\text { Mini-Slots } \\
\text { Contention Mini-Slot }\end{array}$ & : & : & • & : & : & : & : \\
\hline Security mechanism & $\mathrm{o}$ & $\mathrm{o}$ & $\mathrm{O}$ & $\mathrm{o}$ & o & $\mathrm{o}$ & $\mathrm{o}$ \\
\hline $\begin{array}{r}\text { RCST forward link receivers } \\
\text { Single DVB-S } \\
\text { Multiple DVB-S } \\
\text { Single DVB-S2 } \\
\text { Multiple DVB-S2 }\end{array}$ & $\dot{\circ}$ & • & $\dot{\circ}$ & $\stackrel{\bullet}{\circ}$ & $\bullet$ & $\bullet$ & $\begin{array}{l}\mathrm{o} \\
\bullet \\
\end{array}$ \\
\hline $\begin{array}{r}\text { Mobility } \\
\text { Mobility management } \\
\text { Spectrum spreading } \\
\text { Continuous carrier operation } \\
\text { Large uncertainty logon } \\
\text { NLOS Channel countermeasures }\end{array}$ & & & & & & & $\begin{array}{l}\bullet \\
\dot{0} \\
0 \\
\dot{0} \\
\dot{o}\end{array}$ \\
\hline $\begin{array}{ll}: & \text { Minimum Compliance Re } \\
\text { o: } & \text { Optional Compliance Poi }\end{array}$ & uireme & $\overline{\mathrm{RCST}}$ & & & & & \\
\hline
\end{tabular}

Table 4: RCST compliance table

In addition to the standards the Guidelines document [20] has been updates and a separate Guidelines document prepared for the mobile scenarios [21]. The reader is encouraged to refer to these two documents for further details. They are available from the DVB Blue book and are at the time of writing this article going through the ETSI publication and approval procedures.

\section{Conclusions}

In conclusion, it is considered that DVB-S2 \& DVB-RCS can now meet the demanding needs of mobile users. The proposed system configuration together with the related estimated service coverage and user traffic requirements, have been being addressed. 
The main system parameters, i.e. the system architecture and the operational requirements, common to the three envisaged scenarios, i.e. aeronautical, maritime and land mobile scenarios, have been presented.

Regulatory aspects, especially EIRP spectral density limits, have a profound affect upon the system architecture and performance/capacity and as a consequence special measures have been adopted when developing the standard. This is particularly true at $\mathrm{Ku}$-Band and to a lesser extent at Ka-Band.

The plethora of recent and ongoing R\&D activities and trials, as well as the existence of several (proprietary) commercial systems, indicates that there is substantial interest in such systems. It is therefore extremely likely that this new open standard could bring the familiar benefits of economies of scale and vendor independence to such systems.

The RCS+M update is currently the largest and most substantial update of the DVB-RCS specification. With the recent Call for Technologies for Next Generation, RCS+M will be brought forward also to the next generation DVB satellite communications, underlining also the revitalization of the open multivendor DVB-RCS standard for the future international satellite community.

\section{Acknowledgements}

The authors wish to acknowledge the DVB for its support in this work and the valuable discussions held with leading experts in this field who gave their advice and support freely.

Paul Thompson wishes to express his appreciation for the support given to him by the EU SATNEX II NOE. Harald Skinnemoen wishes to thank ESA for supporting the interesting and inspiring chairmanship role of TM-RCS.

\section{References}

[1] DVB-RCS: Digital Video Broadcasting (DVB); Interaction channel for satellite distribution systems: ETSI EN 301790 v1.4.1.

[2] DVB-RCS: Digital Video Broadcasting (DVB); Interaction channel for Satellite Distribution Systems; Guidelines for the use of EN 301790 : ETSI TR 101790.

[3] DVB-S2: Digital Video Broadcasting (DVB); Second generation framing structure, channel coding and modulation systems for Broadcasting, Interactive Services, News Gathering and other broadband satellite applications : ETSI EN 302307 v1.1.1.

[4] DVB-S2: Digital Video Broadcasting (DVB) User guidelines for the second generation system for Broadcasting, Interactive Services, News Gathering and other broadband satellite applications (DVB-S2) : ETSI TR 102376.

[5] Vincent P, et.al., 'Mobile Wideband Global Link sYstem' (MOWGLY) -Aeronautical, Train and Maritime Global High-Speed Satellite Services, Paper I000242 AIAA ICSSC2005 Rome.

[6] Ho-Jin Lee, Deock-Gil Oh, Hokyom Kim, Jae-Myoung Kim, and Sean Kim 'Two-Way Satellite Access System Development For Residential And Mobile Broadband Multimedia Users’ AIAA 21st ICSSC2003, 15-19 April 2003, Yokohama, Japan Paper AIAA 2003-2243.

[7] Yun-Jeong SONG, Min-Su SHIN, Byoung-Hak KIM, Ho-Jin LEE, Young-Keun CHANG, and SungWoong RA, 'Development of Mobile Broadband Satellite Access System for Ka/Ku-band Satellite Communications', IEICE TRANS. COMMUN. (Japan), VOL.E87-B, NO.8 AUGUST 2004, pp 2152 2161. 
[8] Yun-Jeong Song, Deock-Gil Oh, Ho-Jin Lee, 'Development of Mobile Broadband Interactive Satellite Access System for Ka/Ku band’ Paper I000106 AIAA ICSSC2005 Rome.

[9] M. Alvarez Diaz, S. Scalise, G. Sciascia, R. Mura, P. Conforto, H. Ernst, "DVB-S Air Interface over Railroad Satellite Channel: Performance and Extentions", 6th Baiona Workshop on Signal Processing in Communications, Baiona, September 8-10,2003, Universidad de Vigo Spain / IEEE, Proceedings Sixth Baiona Workshop, (2003).

[10] Sciascia, S. Scalise, H. Ernst, R. Mura, "Statistical characterization of the railroad satellite channel at Kuband", International Workshop of COST Actions 272 and 280, ESTEC, Noordwijk, The Netherlands, 2628 May 2003, ESA/ESTEC, Proceedings COST 272/280, (2003).

[11] M. Holzbock, A. Jahn, E. Lutz, "Aeronautical Channel Measurement Trials at K band", 4th Ka Utilization Conference, Venice, Italy, Nov. 1998.

[12] Scalise, S.; Sciascia, G.; Alvarez Diaz, M.; Ernst, H.; Mura, R, Performance of coding and synchronization schemes for a DVB-S based air-interface in the railway environment Vehicular Technology Conference, 2004. VTC 2004-Spring. 2004 IEEE 59th Volume 1, 17-19 May 2004 Page(s):347 - 351 Vol.1

[13] G. E. Corazza and F. Vatalaro, "A statistical model for land mobile satellite channels and its application to nongeostationary orbit systems,” IEEE Trans. Veh. Technol., vol. VT-43, no. 3, pp. 738-742, 1994.

[14] S. Cioni, M. Bertondini, G.E. Corazza, A. Vanelli-Coralli, "Antenna Diversity for DVB-S2 Mobile Services in Railway Environments”, ASMS 2006 Conference, May 2006

[15] Ki-Dong Lee, Deock-Gil Oh, and Ho-Jin Lee, 'Adaptive Control for Delay and Throughput in Broadband GEO Satellite Interactive Channels’, Paper 171, IST mobile summit 2005, Dresden.

[16] 3GPP TS 26.346, Technical Specification Group Services and System Aspects; Multimedia Broadcast/Multicast Service (MBMS); Protocols and codecs (Release 6), V6.3.0 (2005-12).

[17] J. W. Byers, M. Luby, M. Mitzenmacher, A Digital Fountain Approach to Asynchronous Reliable Multicast, Journal of Selected Areas on Comm., October 2002

[18] P. Skoutaridis, C. Kasparis, B. G. Evans, "Simulation of DVB-S2/RCS Performance in a Vehicular Satellite Environment,” AIAA Int. Comm. Satel. System. Conf., San Diego, USA, 10-14 June 2006.

[19] DVB BlueBook A054r4.1 (01/2009) Interaction channel for Satellite Distribution Systems (draft EN 301 790 V1.5.1 - DVB-RCS+M)

[20] DVB BlueBook A063r3 (10/2008) Guidelines for the Implementation and Usage of the DVB Interaction Channel for Satellite Distribution Systems (dTR 101790 V.1.4.1)

[21] DVB BlueBook A130 (11/2008) Interaction channel for Satellite Distribution Systems; Guidelines for the use of EN 301790 in mobile scenarios (dTS 102768 V.1.1.1) 